\title{
Funding APCs from the research funder's seat: Findings from the EC FP7 Post-Grant Open Access Pilot
}

\author{
Pablo De-Castro; Gwen Franck
}

How to cite this article:

De-Castro, Pablo; Franck, Gwen (2019). "Funding APCs from the research funder's seat: Findings from the EC FP7 Post-Grant Open Access Pilot". El profesional de la información, v. 28, n. 4, e280413.

https://doi.org/10.3145/epi.2019.jul.13

Manuscript received on $31^{\text {th }}$ Dec 2018 Accepted on $10^{\text {th }}$ May 2019

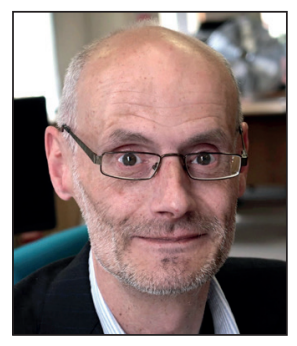

Pablo De-Castro $\square$ http://orcid.org/0000-0001-6300-1033

University of Strathclyde Library 101 St James Road, Glasgow G4 ONS, UK pablo.de-castro@strath.ac.uk

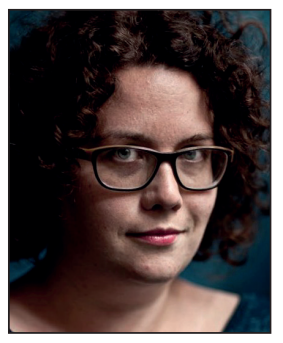

Gwen Franck https://orcid.org/0000-0002-9719-0570

Association of European Research Libraries (LIBER)

Prins Willem-Alexanderhof, 5. 2595 BE

The Hague, Netherlands gwen.franck@kb.nl

\begin{abstract}
Some way already into the transition towards a fully Open Access scholarly communications landscape, it is useful to take a look at the findings arising from a pioneering pilot initiative launched by the European Commission to fund Article Processing Charges (APCs) associated to publications stemming from finished European FP7 projects. The article describes the methodology and results for the initiative. It also argues that beyond the flavour of the specific Open Access policy chosen by specific countries, this kind of supranational APC funding initiative could become a key element -alongside instruments like national-level offsetting agreements- to ensure a level playing field for researchers. It's finally argued that the no-hybrid policy applied in the implementation of this APC funding initiative is a suitable mechanism to contain the costs and prevent further publishing market concentration. Detailed results are provided for the close to 3-year funding exercise, showing for instance the widespread uptake across EU countries albeit with significant differences across regions. Funded publishers and journal titles are analysed, together with the evolution of the average APC fee. A summary of lessons learnt is offered at the end of the paper, both for institutions and funders.
\end{abstract}

\section{Keywords}

Open access; Gold open access; Article processing charges; APC; Research publishing; Scholarly communication.

\section{Financing}

The FP7 Post-Grant Open Access Pilot has been funded by the European Commission under the OpenAIRE2020 H2020 project, grant number 643410.

Acknowledgments

The authors would like to thank the two anonymous reviewers for their constructive feedback that has significantly improved the paper.

\section{Supplementary Materials}

The full dataset of FP7-Post-Grant Open Access Pilot-funded requests as of Feb $28^{\text {th }}, 2018$ is available online on https://doi.org/10.5281/zenodo.998041

\section{Author contributions}

Both authors have consecutively worked as FP7 Post-Grant Open Access Pilot coordinators at the Association of European Research Libraries (LIBER) in The Hague, PdC in the period 2015-2016 and GF from 2017 onwards. This work is the result of their discussions. PdC has written the article and GF has extracted and provided the updated datasets.

Conflicts of interest

The authors declare no conflict of interest. The funding sponsors had no role in the design of the study; in the collection, analyses, or interpretation of data; in the writing of the manuscript, and in the decision to publish the results. 


\section{The FP7 Post-Grant Open Access Pilot: Design and implementation}

\subsection{Introduction}

The FP7 Post-Grant Open Access Pilot was launched by the European Commission in May 2015 as a 2-year experimental initiative to explore the workflows around APC funding for publications arising from finished FP7 projects. With a budget of 4 million euros specifically allocated for the purpose, the initiative set out to cover the Open Access publishing expenses for post-grant publications arising from over 8,000 eligible FP7 projects. It meant a first attempt by this key research funder to support APC-based Gold Open Access in an 'external' way from the project grants themselves. ${ }^{1}$ The fact that once the original April 30 30 h 2017 end-date for the initiative was reached the project was extended for an additional ten months (European Commission, 2017) provides a solid piece of evidence for its perceived usefulness. Following this extension, the pilot officially ended on Feb $28^{\text {th }}, 2018$.

The at that time unique post-grant character of the funding initiative ${ }^{2}$ was a way to acknowledge the fact that most publications resulting from funded projects are produced by the time the project has already finished, which means that the project grant is not available anymore to support any Open Access publishing costs that may arise at that later stage. The limited eligibility for APC funding resulting from this post-grant nature -which involved significant dissemination challenges outlined below- was otherwise very well suited to the exploratory nature of the funding initiative.

Since the research funder had no previous example for this sort of funding scheme to build upon, the FP7 Post-Grant funding initiative had to be designed from scratch. Policy elements like the time-window after the project end-date during which publications would be allowed to apply for APC funding or whether or not manuscripts accepted in hybrid journals would be eligible for funding were defined after a comprehensive engagement process with the Open Access community via the OpenAIRE project. The role played in this process by all the OpenAIRE partners involved in the initiative -LIBER and SURF in the Netherlands, the University College London and the Jisc in the UK, the University of Göttingen in Germany, the University of Athens and Athena Research Centre in Greece, and the Italian Research Council in Italy- must be acknowledged as a key element for its success. The roles played in the initiative by these institutions are summarised in the figure below.

\subsection{Funding APC-based Gold Open Access}

The FP7 Post-Grant Open Access Pilot was conceived as a blanket-funding initiative, meaning it covered a very wide geographic area without having any particular restriction on the funding distribution by institutions. At the time the pilot was launched there were a good number of previous initiatives usually at a national level, to implement this kind of blanket funding. Research funding agencies like the Research Councils UK (RCUK, 2012) and the Wellcome Trust (Wellco$m e, 2014)$ in the United Kingdom, the German Research Foundation (DFG, 2017) in Germany, and the FWF (FWF, 2014) in Austria had already launched national-level Gold Open Access funding initiatives similar to this European-wide one. These national funder-driven efforts, often based on rather similar policies are in fact arising in an increasing number of European countries. An equally growing number of institutional Open Access funds for supporting Gold Open Access

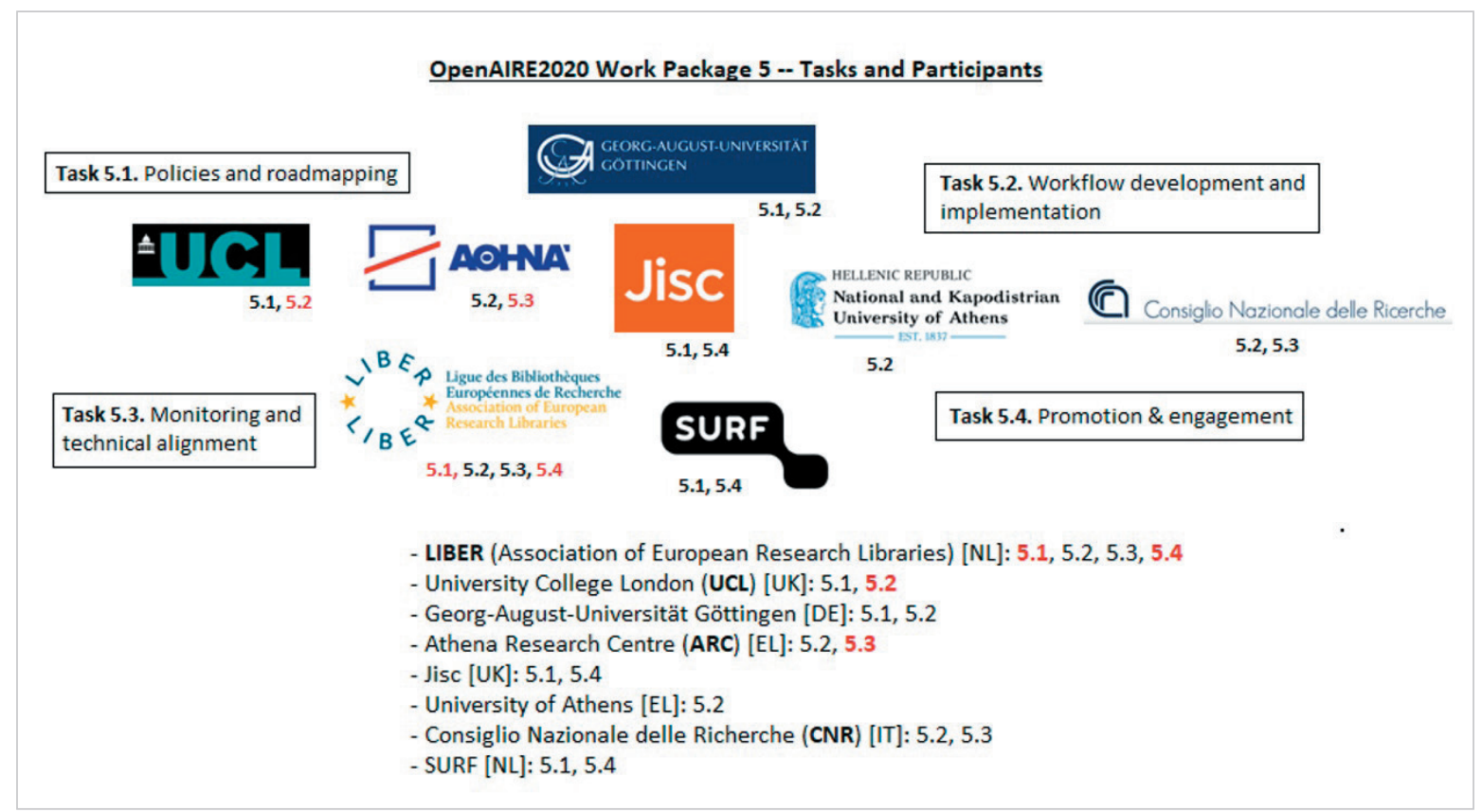

Figure 1. OpenAIRE partners involved in the EC FP7 Post-Grant Open Access Pilot and their tasks (task coordinators in red colour) 
provide an additional source of funding for researchers. The ongoing transition towards full Open Access (MPDL, 2016) is mainly based on these, together with the ever more frequent and relevant offsetting agreements (Geschuhn; Stone, 2017).

Some basic questions raised by this complex funding landscape are: is the overlapping of these multiple funding initiatives decreasing their efficiency? Could these overlapping policies somehow be adjusted to mutually reinforce their impact? What would be the best way to achieve this?

\section{By running an APC funding project in a} centralised way, the challenges and the findings of the initiative are directly experienced by the research funder, which finds itself in a potentially privileged position to engage with different stakeholders -researchers, institutions, publishers and other funders

It's still early days to provide evidence-based answers to these questions, but trying to collect such evidence was part of the remit of the FP7 Post-Grant Open Access Pilot. ${ }^{3}$ While the exercise was running, the emphasis was mainly being made on collecting the widest possible sample for data on APC payments across institutions and funding initiatives (De-Castro, 2016a). This allows an increased level of transparency in a complex and relatively opaque business environment. However, these are only the first steps that need to be taken on the way to designing and implementing the most effective policy actions.

There were two key differences between this FP7 Post-Grant Open Access Pilot and most national-and funder-level initiatives in various countries.

- The first one was its degree of diversity as a result of its sheer geographic coverage. While for some of the countries and institutions being supported there could be an overlap with other funding policies, the initiative was also implemented in areas where no alternative source of funding was available. The possibility to compare the results under different research funding conditions was then a unique feature of this pilot.

- The second big difference was that while most national-level initiatives are run in a decentralised way via institutions, the EC FP7 Post-Grant Open Access Pilot was almost exclusively implemented in a centralised way by the funder and not by distributing its funding across a number of institutions. This means that the challenges and the findings of the initiative are directly experienced by the funder, which finds itself in a potentially privileged position to engage with different stakeholders -researchers, institutions, publishers and other funders.

\subsection{A difficult initiative to disseminate}

Any post-grant funding initiative aimed to cover the Open Access publishing fees for publications arising from finished projects like this one should ideally be disseminated at the beginning of such projects. This would allow researchers -and above all, the project coordinators- to keep the funding opportunity in mind by the time the project reaches its end-date. This typically means several years, but if precise funding guidelines were provided at the project start, researchers would be able to return to them and benefit from the funding in due time.

This is of course not the way a pilot initiative works. A pilot is launched in the middle of a research framework programme with thousands of potentially eligible projects running. Some of them will not be eligible for any post-grant funding because they will still be running while the pilot is implemented. Other ones will have finished too early to benefit from the funding. It is then a rough approach in the multiple senses of the word. But there are many lessons to be learnt from a pilot in such circumstances.

One of the main ones is that it's difficult to reach out to potentially eligible researchers from the funder's seat. Once projects reach their end-date, the project partner networks are still there but become much looser. It is unclear whether letting the project coordinator know about a post-grant funding opportunity will allow the message to reach every partner that was involved in the project, even in the rather frequent case that its researchers have moved to a different institution. For a funding initiative like this one to be reasonably effective, it should target both project coordinators and partners. This can only be achieved by partially relying on institutions to do the dissemination work, but even this is far from straightforward in a competitive environment between funding initiati-

\section{$\underset{\text { OPeAARE }}{\oplus}$ Policy Guidelines}

- The FP7 project should have finished by the time the funding is requested, but no longer than two years ago;

- A maximum of three publications will be funded per eligible FP7 project as a means to ensure a fair distribution of the funding across projects;

- Funding requests must be submitted once the publication has been accepted;

- Publications submitted to hybrid journals will not be funded, but only those accepted at fully Open Access journals;

- The following funding caps apply to this funding: EUR 2,000 for research articles and EUR 6,000 for monographs;

- The final version of the funded output must be deposited in an OpenAIREcompliant Open Access repository;

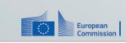

Figure 2. Summary of the FP7 Post-Grant Open Access Pilot policy guidelines 
ves where institutions are not offered any particular incentive for their direct involvement in the implementation of the new post-grant initiative.

Having this wide-scoped FP7 Post-Grant Open Access Pilot implemented under the OpenAIRE2020 project was one of the wisest choices for this initiative. Being a project with over 50 partners with many years of experience, OpenAIRE offered a comprehensive network of reliable institutions that provided the required support for dissemination purposes as part of their regular work for promoting Open Access. Some challenges remained, such as the fact that OpenAIRE has traditionally made emphasis above all on the Green Route to Open Access -OpenAIRE was originally conceived as a repository infrastructure. The rationale for the pilot partner team was that a right dissemination approach towards the OpenAIRE National Open Access Desks (NOADs) would allow the ever less relevant Green vs Gold controversy to be overlooked for the benefit of researchers.

Besides the issues around reaching the potentially eligible researchers, another major problem of this post-grant funding initiative -and potentially of any post-grant funding initiative- is the inevitable complexity of its policy guidelines. The main elements in the policy applied by this pilot are summarized in figure 2 . These elements are not significantly different from the policy guidelines issued by other national-level blanket-funding initiatives, given that in line with the findings from the Pasteur4OA project (Pasteur4OA, 2014), a certain level of alignment with other funders' policies was perceived to be a key goal to keep in mind while issuing the guidelines for the FP7 Post-Grant Open Access Pilot. But the guidelines above are complex, especially when compared to much simpler national-level policies with no funding cap and no restriction to publish in hybrid titles. This complexity meant that the dissemination side of the initiative would need to provide comprehensive clarification to researchers and institutions on the different aspects of the policy.

When comparing this to an alternative funding option such as an offsetting agreement or an institutional Gold Open Access fund where the author's affiliation will be the sole criteria to get the funding awarded, the magnitude of the dissemination challenges faced by this initiative becomes clear. An intensive effort was however made in this area by both the coordination of the initiative and the whole OpenAIRE network -plus many institutional libraries and research offices that have seen the value of this exercise and provided their generous collaboration. This effective cross-institutional collaboration at an international scale was another valuable project finding: this initiative provided a glimpse into the possibility of having an all-European network of research support services operating far beyond the universities to provide support to publicly-funded researchers regardless of their affiliation.

\subsection{Researchers' attitudes}

As revealed by the survey carried out within the project analysis (Research Consulting, 2017), most researchers saw this initiative as a very valuable additional piece of support for the European Commission's Open Access policies. Many researchers stated that had it not been for this FP7 Post-Grant Open Access Pilot, they would not have been able to publish in an Open Access journal at all. Early career researchers with limited access to funding were particularly grateful about the funding initiative and have often included this specific support in their manuscript acknowledgements.

A potentially useful indicator for the perceived value of this initiative is the high rate of recurrence in funding applications. Even if this is not the behaviour that could in principle be expected from projects with dozens of partners, it was not infrequent that the maximum of three funded publications awarded to a specific project as per the policy guidelines above ended up being granted to the same author. In this sense, the funding initiative seemed sometimes to operate like a well-kept secret: authors who had taken the effort to understand the requirements of the funding opportunity would keep coming back for more. And as long as the project coordinator would not object to it, they would get it: the initiative was rolled out on a first come-first served basis.

However, not all authors were that happy about the initiative: there were a significant number of complaints against the no-hybrid policy, a key feature in this FP7 Post-Grant OA Pilot. This policy element is completely aligned with the policies of many national-level research funders in Europe, so it's not necessary to explain its motivation here (Frantsvåg, 2015). It is true however that by restricting the funding to papers published in fully Open Access journals the initiative introduced a disciplinary bias, given the rather uneven distribution of these journals across research fields at the moment. Researchers in engineering, specific areas of applied physics and specific areas of social sciences and humanities among others strongly argued that they had no way to become eligible for this postgrant funding because they lacked the appropriate pu-
Many researchers stated that had it not been for this FP7 Post-Grant Open Access Pilot, they would not have been able to publish in an Open Access journal at all. Early career researchers with limited access to funding were particularly grateful about the support 
blishing venues. This is changing very fast nowadays, and contributing to some extent to this change -and promoting fully Open Access publishing- was meant to be one of the main objectives of this initiative and of its policy guidelines.

A significant number of comments was also received questioning the two-year funding eligibility time-window beyond a project's end-date. Some researchers argued that given the specific circumstances of their projects, a three-year window would have been more appropriate, such as it was applied later by a similar national post-grant funding initiative in Germany (BMBF, 2017). The eligibility time-window has always been applied with some flexibility in any case: at the start of the initiative, to enable a wider implementation, and later on, to partially compensate the occasionally very long peer-review periods for the manuscripts.

There were also queries about the eligibility of specific projects. Calls within the very wide FP7 programme are extremely complex and it's often unexpectedly hard to tell what is and what isn't an FP7-funded project, since the project funding may often be partial. The criteria applied by this initiative was that any project with a 6-digit grant number listed in the Cordis database would be eligible for funding. This did in turn provide opportunities for a certain amount of internal housekeeping on the funder's side in cases where potentially eligible calls would not have their project data delivered into the official project database.

When discussing researchers' attitudes it's finally worth mentioning the large number of conversations held with potentially eligible authors to discuss their FP7 project circumstances and their views on the funding initiative. These private exchanges, unreported elsewhere, provide the basis for many of the project's findings and were perhaps the most valuable area of activity for the initiative. Research support services in general and research libraries in particular are also in a good position to hold fact-finding conversations with institutional authors. Researchers talking to their project funder will however take the opportunity to query other areas of the funders' policies -such as research data management and the EC Open Data Pilot- thus turning the APC funding exercise into a suitable mechanism for training.

\subsection{The OpenAIRE system for collecting and processing funding requests}

One of the key outputs from the FP7 Post-Grant Open Access Pilot has been the OpenAIRE system for collecting and processing funding requests developed at Athena Research Centre. ${ }^{4}$ This comprehensive open source system was conceived to serve authors, institutions and publishers following a series of workflows designed at the start of the project describing the many different ways in which different stakeholders could engage with the funding initiative. These would include among others:

- the submission of queries and funding applications by authors;

- the approval and payment of eligible requests by the system moderators;

- the submission of funding applications on behalf of authors by institutional support services like libraries and research offices, and

- the management of pre-paid accounts by selected publishers, plus the occasional institution (Van-Gorp, 2016).

Funding initiatives of this scale tend to heavily rely on decentralised workflows. This is usually realised via the transferring of block grants, so that their dissemination and implementation can be carried out at institutions closer to the end-users, the researchers involved in eligible projects (RCUK, 2016). However, for this pilot this decentralisation was out of the question for two main reasons:

- first, because there were too many candidate organisations ${ }^{5}$, and

- second, because these would not be just universities and research centres, but any partner anywhere in the world involved in an FP7 project, meaning research foundations, hospitals, SMEs and other kinds of stakeholders typically not part of the Open Access community.

It was then critical for a centralised, funder-driven APC funding initiative aimed to serve thousands of researchers to be able to rely on a platform that would provide equal opportunities to access the funding to all these stakeholders.

Monitoring and reporting were additional key features the system was designed to support (see screenshot on figure 3). The reporting feature covered different areas such as:

- total number of funded requests received and their distribution by journal title, publisher, FP7 project type, research-performing organisation, and/or country;

- number of rejected requests and reasons for their rejection;

- progress in the budget spending, both as a whole and for pre-paid funds deposited with specific publishers.

The area of monitoring would in turn allow the system administrators to explore the number and type of registered users with the system, the status of the many funding applications that would simultaneously be processed or number of funding applications already awarded to specific FP7 projects (which was limited as per the policy guidelines above). 
Given the limited amount of human resources involved in the project implementation, a centralised system critically offered the opportunity, once it was fine-tuned following the first months of operation, to run the funding initiative in a nearly automated way with just a light-touch overseeing by the project team.

This is not a route commonly followed by other research funders, possibly because of the complexity involved in the process. Large funders will typically choose a decentralised workflow and the subsequent aggregation of the reporting information provided by institutions, whereas smaller funders that implement a centralised APC funding workflow will usually lack the resources to face the significant development effort involved in designing and implementing a specific purpose-built system. ${ }^{6}$ This is however an area in the domain of research support infrastructure around Gold Open Access implementation where innovation is constantly taking place ${ }^{7}$ and the open source platform developed by OpenAIRE could well be worth revisiting for its re-use by other funders besides the $E C$ and even by institutions processing a large amount of APC funding requests.

\subsection{Pre-payment agreements with publishers}

The pre-payment agreements that OpenAIRE signed with different publishers to ensure a smoother implementation of the FP7 Post-Grant Open Access Pilot remain one of the most unique and interesting features of the whole initiative. While carried out in a totally transparent way and open to the participation of any interested stakeholder, ${ }^{8}$ these agree- $^{-}$ ments were mostly worked out with fully Open Access publishers like Ubiquity Press, Copernicus or BioMed Central. This was a direct result of the pilot's policy not to fund APCs for accepted manuscripts in hybrid journals, which made it far more attractive to publishers with a large number of fully Open Access journals. This notwithstanding, publishers with a significant number of hybrid titles in their portfolio like BMJ or Wiley also joined this implementation mechanism.

These agreements mainly aimed to simplify the funding process by directly working with the publishers to identify - and award APC funding to- eligible manuscripts at acceptance time. This way the authors would not need to submit any funding request anymore but would instead be directly contacted by the pilot coordination in order to inform them that their accepted manuscript, whose data had been shared with the pilot by the publisher, was eligible for APC funding under the FP7 Post-Grant initiative. This resulted in a steep increase in the awareness of the funding initiative by eligible FP7 project partners and coordinators, many of whom would subsequently get in touch upon submission of a new manuscript to an eligible (fully Open Access) title.

Moreover, the implementation of this early funding mechanism required a close collaboration with the publishers in order to devise mechanisms for the correct identification of eligible papers on their manuscript processing systems. Because of the key role played by the funding acknowledgement in the manuscripts, conversations were held not just with the technical teams on the publishers' side, but also with Crossref. Given the fact that only manuscripts accepted within two years of the project's end-date were eligible for funding and given the uncertainty about the reviewing times, the workflow would typically involve a manual eligibility checking by the pilot coordination of the list of candidate manuscripts periodically sent by the publishers which acknowledged FP7 projects. The discussions on the most suitable technical process to identify eligible FP7 projects provided opportunities for a particularly fruitful collaboration between the research funder and the publishers in areas like direct dissemination of the funding initiative to authors from the publisher or the SWORD-mediated automatic deposit of FP7-funded articles and their metadata into Zenodo. One of the main findings of this initiative has been in fact that a more consistent implementation of this funder-publisher collaboration would massively simplify the very complex APC funding workflows that funders, institutions and publishers alike were struggling with at the time. ${ }^{9}$ Similarly centralised funding workflows implemented by other funders -eg the elegant approach followed by the Gates Foundation via their Chronos platform- provide a solution to the intrinsic complexity involved in a many-to-many relationship between publishers, authors and institutions. Moreover, given that complex 
bureaucratic workflows often stand in the way of implementing a specific funding policy, their simplification is likely to help funders focus on the design of the most effective policy possible in each case.

Also worth mentioning are the parallel agreements signed with book publishers within this collaboration framework, since this funding initiative also covered book chapters, monographs and edited volumes arising from finished FP7 projects. Open Access book publishers like Ubiquity Press, InTech or River played a proactive role in the implementation of the pilot by raising awareness of the funding opportunity among the authors they would approach for promoting their publishing services. The amount of funded works in these categories was significantly lower than for journal articles, but extensive conversations with FP7-funded authors provided opportunities for exploring their attitudes. One of the pilot's main findings in this regard was that there is still a very strong preference among authors for the prestige book publishing brands regardless of their Open Access publishing models and of the Book Processing Charges (BPC) they apply. However, it's mainly the research funders' role to gradually make it clear to the researchers involved in the projects they fund that Open Access is an important aspect to bear in mind in that choice of publishing venue.

\subsection{The alternative funding mechanism for APC-free Open Access journals and platforms}

From the very early stages in the discussions around the implementation of the initiative, it became evident that a parallel mechanism would need to be designed to support APC-free Gold Open Access. The main argument to support this view was that a very significant fraction of the Gold Open Access publishing initiatives does not rely on an APC-based business model (Morrison, 2015), so it would be unfair to focus the funding initiative just on APC payments. The challenge was then to define some kind of "APC-equivalent" funding mechanism for these other journals and platforms -a mechanism that would still need to keep some link to the FP7 outputs too.

A consultation process with the various stakeholders involved in APC-free Open Access publishing -universities, institutional consortia, learned societies, non-profit associations- was carried out addressing both the 'cultural' and the technical aspects of possible funding mechanisms. As a result of these, a call for proposals was issued (OpenAIRE, 2016) to fund technical enhancements for APC-free Open Access journals that would contribute to make them more attractive for future submissions by EU-funded authors. In order to preserve the connection to the FP7 programme, titles were only able to apply for funding under this call if they had published at least two FP7-funded articles by the time their funding proposal was submitted to OpenAIRE.

Suggested technical improvements for these APC-free journals and platforms included among others areas like OpenAI$R E$ compliance, OJS platform upgrade, article-level information delivery to the Directory of Open Access Journals (DOAJ), production of XML files or ORCID implementation. Applicants were requested to specify a budget for their technical improvement plan that the FP7 Post-Grant OA Pilot would fund if it fell within the limits established in the call.

Eleven proposals from ten countries were selected for funding and they were given nine months to implement their suggested enhancement plans. Funded bids under this alternative funding mechanism showed a far more balanced geographic distribution across regions than the APC funding figures shown in the following section, and included both standalone journals and platforms with multiple APC-free Open Access titles. Technical improvement plans from different funded bids showed numerous overlapping areas, which led the pilot coordination to hold an Alternative Funding Mechanism Workshop (De-Castro, 2016b) where representatives from the funded bids were able to meet and discuss common challenges and possible avenues for informal collaboration.
There is still a very strong preference among [book] authors for the prestige book publishing brands regardless of their Open Access publishing models and of the Book Processing Charges (BPC) they apply. However, it's mainly the research funders' role to gradually make it clear to the researchers involved in the projects they fund that Open Access is an important aspect to bear in mind in their choice of publishing venue

This alternative funding mechanism offered an opportunity to explore in more detail the OpenAIRE interface with institutional Open Access publishers: because the OpenAIRE data provider statistics (OpenAIRE, 2018) show a far larger proportion of literature repositories than Open Access journals, the emphasis had traditionally been placed on the guidance for repository compliance. This alternative funding mechanism provided the opportunity to gather a network of stakeholders using various software platforms that were keen to discuss their requirements -both with regard to Ope$n A I R E$ compliance and in other areas- with the OpenAIRE technical coordination in Bielefeld.

In order to share the appropriate information with those bids left unfunded and beyond, the call for proposals required all funded bids to produce a report by the end of their technical enhancement work explaining their original improve- 
ment plan and its results (Šipka, 2017). These reports from funded bids are also an additional dissemination mechanism for an area of activity within this FP7 Post-Grant OA Pilot that could well be of interest for a range of effectively Open Access titles out there that fail to meet specific technical criteria that would allow them to join directories like the DOAJ.

Same as the main APC funding side of the initiative was extended beyond its original deadline, the alternative funding mechanism also issued a second round of funding once it was announced that the project would run for longer than originally planned. This second round of funding was more geared towards the exploration of new publishing models and provided support to stakeholders like the Fair Open Access Alliance (FOAA) or the Open Library of Humanities (OLH). A specific workshop -"Beyond APCs - OpenAIRE workshop on alternative open access publishing business models"- was again held to coordinate the different funded stakeholders (Jobmann, 2018).

\section{Project results}

This section provides a summary of the FP7 Post-Grant Open Access Pilot results. The analysis covers areas like the average APC fees paid and their distribution across countries, institutions and FP7 projects, as well as across journals, publishers and document types.

All the figures provided in the tables and graphs are dated Feb $28^{\text {th }}, 2018$, which is the official end-date for the FP7 PostGrant OA Pilot. However, it should be kept in mind that the dataset for granted APC/BPC funding requests on which the results provided below are based is not fully final at the time of writing. As explained in the readme section of the publicly available full dataset (Franck, 2018), this is because a number of requests were still in 'under processing' status by the time the pilot officially stopped taking in any new ones by the end of February 2018. Some of these may not get completed though, and while this could mean minor changes in the final figures with regard to the ones provided here, the authors have considered it's still worth sharing the results and findings as they stand, since the dataset is large enough for these potential minor changes not to be too significant. The final dataset will be updated in Zenodo once all the remaining accounting is wrapped up.

\subsection{APC funding distribution across countries, institutions and FP7 projects}

There was some uncertainty at the start of the initiative on the kind of funding distribution by country that could be expected. Would the funding mainly go to countries where no other sources of APC funding were available, or would it follow the 'Matthew effect' instead, meaning that those countries where the APC funding mechanisms were already well-established would have an advantage for the awareness-raising and implementation of what for them was just an additional funding mechanism?

The sheer concept of funding distribution by country is a slippery one anyway when dealing with strongly international projects whose multiple partners span a wide range of geographies. Still, this made sense for an initiative relying for its dissemination on a wide network of national-level OpenAIRE contact points or NOADs. The methodological approach chosen for monitoring this distribution, to some extent a result of the way the funding requests were coded in the system described above, assigned every granted funding request to the country for the institution with which the researcher who requested the funding was presently affiliated. Other approaches could have been possible -such as allocating the granted funding to the country where the project coordination was based - that would show a slightly different picture, possibly even more concentrated on
Table 1. Total number and percentage of granted funding requests by country

\begin{tabular}{|c|c|c|}
\hline Country & Funded requests & $\%$ \\
\hline United Kingdom & 169 & 15.74 \\
\hline Spain & 152 & 14.15 \\
\hline Italy & 126 & 11.73 \\
\hline Germany & 116 & 10.80 \\
\hline Netherlands & 84 & 7.82 \\
\hline France & 49 & 4.56 \\
\hline Greece, Switzerland & 38 & 3.54 \\
\hline Austria & 36 & 3.35 \\
\hline Ireland, Sweden & 30 & 2.79 \\
\hline Belgium & 24 & 2.23 \\
\hline Denmark, & 23 & 2.14 \\
\hline Finland & 21 & 1.96 \\
\hline Hungary, Israel & 18 & 1.68 \\
\hline Portugal & 16 & 1.49 \\
\hline Serbia & 15 & 1.40 \\
\hline Norway & 11 & 1.02 \\
\hline Turkey & 10 & 0.93 \\
\hline Slovenia & 9 & 0.84 \\
\hline Poland & 6 & 0.56 \\
\hline Lithuania & 5 & 0.47 \\
\hline Czech Republic & 4 & 0.37 \\
\hline Cyprus, Russia, South Africa & 3 & 0.28 \\
\hline Australia, Croatia, Tanzania, U.S. & 2 & 0.19 \\
\hline $\begin{array}{l}\text { Belarus, Bulgaria, Burkina Faso, Iceland, India, } \\
\text { Luxembourg, Mexico, Slovakia, Ukraine }\end{array}$ & 1 & 0.09 \\
\hline TOTAL & 1,074 & \\
\hline
\end{tabular}


countries with a large number of FP7 projects. The full funding dataset for the initiative is openly available so that these alternative approaches beyond a reasonably comprehensive summary may be explored.

Table 1 shows the actual distribution of funded APCs by country at the official end-date for the initiative, i.e. Feb $28^{\text {th }}, 2018$. Interestingly, the distribution -based on over 1,000 granted funding requests- follows neither of the patterns originally suspected. While there are a few unmistakable patterns in it, the geographic "friendliness towards Gold Open Access" is definitely not one of them: the two countries that have received the highest number of funded APCs, the UK and Spain, have totally different Open Access policies in this regard. ${ }^{10}$ The key element that both countries share is actually the very large number of FP7 projects they take part in (European Union, 2013).

'Large' countries - with regard to the number of awarded FP7 projects rather than in size- tend in fact to feature in high positions on the table. On top of that there is a very clear bias in the distribution towards Western Europe: all EU-15 countries are listed in the top 20 positions, while the best-placed Central/Eastern European country (Hungary) is on place 15. This bias is the result of a very complex mix of cultural and socio-economic factors and the reasons behind it would be worth a deeper investigation. Evidence collected during this pilot suggests that the present level of APC fees will critically not allow the APC-based business model to succeed in regions where Open Access policies are weaker or are not there yet -meaning a much lower awareness of the value of Open Access among researchers.

The worldwide nature of the APC funding is also worth mentioning: the fact that APC funding was granted to FP7 project partners in places as geographically remote from the EU as Mexico or South Africa provides evidence for the deeply international nature of FP7-funded research. Researchers in countries outside the EU like Israel or Turkey were particularly active in requesting funding from this pilot and both countries also feature in the top 20 as a result.

Another indicator closely followed by the project was the distribution of funding across institutions. The top places on the list of granted funding requests typically show organisations where an institutional library or research office has taken the time to identify and reach out to researchers involved in eligible FP7 projects. This correlation between number of granted requests and an effective internal dissemination strategy at institutions gradually became weaker with the increasing relevance of the pre-payment schemes with publishers, where institutional advocacy did not play any role anymore. However, many of the most successful institutions did design and implement efficient advocacy schemes, some of which were described in specific posts on the OpenAIRE blog (Galimberti, 2016; Van-Gorp, 2016; Muñoz, 2016).

The total number of FP7 projects that have received APC funding from this FP7 Post-Grant Open Access Pilot provides an insight into the effectiveness of the initiative in terms of engaging with the whole research framework programme. The number of funded FP7 projects by the end of the pilot has been 765. Keeping in mind that the total number of eligible FP7 projects was in excess of 8,000 , the rate of use of the funding opportunity stands at just under $10 \%$.

The dissemination challenges explained in section 1.3 above, the pioneering nature of the initiative and its short duration and limited amount of human resources all account for its relatively low uptake when considering the total number of potential candidates. This figure for the total number of funded projects is however well above the most optimistic expectations at the time the initiative was launched in April 2015 and provides a significant sample for analysis.
Table 2. The 20 institutions with the highest number and percentage of funded requests

\begin{tabular}{|c|c|c|}
\hline Institution & $\begin{array}{l}\text { Granted funding } \\
\text { requests }\end{array}$ & $\%$ \\
\hline Spanish National Research Council (CSIC) & 33 & 3.07 \\
\hline Radboud Universiteit Nijmegen/St Radboud UMC ${ }^{11}$ & 23 & 2.14 \\
\hline University of Oxford & 21 & 1.96 \\
\hline Universidad Politécnica de Madrid & 19 & 1.77 \\
\hline Italian National Research Council (CNR) & 17 & 1.58 \\
\hline Karolinska Institutet & 15 & 1.40 \\
\hline University College Dublin & 14 & 1.30 \\
\hline Università degli Studi di Milano & 13 & 1.21 \\
\hline University of Bristol & 12 & 1.12 \\
\hline University of Bologna & 12 & 1.12 \\
\hline Helmholtz Association & 11 & 1.02 \\
\hline Universiteit Leiden/Leids UMC & 11 & 1.02 \\
\hline Universität Bern & 10 & 0.93 \\
\hline Universität Bielefeld ${ }^{11}$ & 10 & 0.93 \\
\hline University College London & 10 & 0.93 \\
\hline University of Helsinki & 10 & 0.93 \\
\hline Université Pierre et Marie Curie & 10 & 0.93 \\
\hline Aarhus University & 9 & 0.84 \\
\hline ETH Zürich & 9 & 0.84 \\
\hline Politecnico di Milano & 9 & 0.84 \\
\hline Universitat de Barcelona & 9 & 0.84 \\
\hline
\end{tabular}


A first aspect that was analysed was how many of these 765 funded FP7 projects were fully funded from a perspective of this initiative, i.e. were awarded the maximum funding for 3 APCs: these were 75 projects or $9.8 \%$ of the total, while 149 projects were granted 2 funding requests and 541 just one.

The distribution by project category was also analysed. Table 3 below shows the project distribution by research area for the total number of FP7 projects that received funding from the post-grant funding initiative.

Table 3. Funded FP7 projects by research area

\begin{tabular}{|c|c|c|}
\hline Project research area & No of funded projects & $\%$ \\
\hline Marie-Curie Actions & 224 & 29.28 \\
\hline European Research Council & 104 & 13.59 \\
\hline Information and Communication Technologies & 104 & 13.59 \\
\hline Health & 100 & 13.07 \\
\hline Environment (including Climate change) & 51 & 6.67 \\
\hline Food, Agriculture and Fisheries, and Biotechnology & 49 & 6.40 \\
\hline Nanosciences, Nanotechnologies, Materials and new Production Technologies & 31 & 4.05 \\
\hline Research for the benefit of SMEs & 17 & 2.22 \\
\hline Research Infrastructures & 14 & 1.83 \\
\hline Research Potential & 13 & 1.70 \\
\hline Space & 12 & 1.57 \\
\hline Energy & 10 & 1.31 \\
\hline Transport (including Aeronautics) & 10 & 1.31 \\
\hline Socio-economic Sciences and Humanities & 8 & 1.05 \\
\hline Joint Technology Initiatives (JTI) & 7 & 0.92 \\
\hline Security & 5 & 0.65 \\
\hline Science in Society & 4 & 0.52 \\
\hline Euratom-Fission & 1 & 0.13 \\
\hline International Cooperation & 1 & 0.13 \\
\hline TOTAL & 765 & 100 \\
\hline
\end{tabular}

This distribution of funded FP7 projects shows four large categories on top (PEOPLE, ICT, ERC, HEALTH), with Marie Curie projects clearly standing out -these Marie-Curie Actions are normally smaller projects and the internal negotiation for approving the funding for a specific project partner may as a result be much simpler than for larger FP7 projects. The distribution follows the internal project categories available for the FP7 research programme and does only approximately represent a classification by research discipline, given that some of the categories are organisational rather than scientific.

\subsection{Choice of journal titles and funded output types}

A factor directly impacting any classification by research area is the uneven availability of suitable fully Open Access titles across research disciplines. The Directory of Open Access Journals (DOAJ) provided the basis for the journal titles to be supported by this FP7 Post-Grant OA Pilot, but certain shortcomings became evident as the funding initiative progressed. For instance, while a comprehensive list of Open Access journals worldwide is a very valuable resource for the Open Access community, it is far less so for a group of well-funded researchers that are looking for the top journals in their field that meet a specific set of funding requirements which in this case involved being fully Open Access. Moreover, this FP7 Post-Grant OA Pilot was rolled out in a shifting scholarly publishing landscape where a significant number of publishers were either flipping some of their hybrid titles to fully Open Access business models (such as Wiley or BMJ) or launching new Open Access titles (eg ACS, IEEE). These very recently flipped or launched titles would often not have a DOAJ entry yet, which led to the production of a quickly growing list of fully OA journals that had already been funded by the initiative. This list was regularly updated on a post that soon became the most popular one in the OpenAIRE blog (De-Castro, 2015) as a result of the many visits by eligible researchers looking for a suitable title to submit their manuscripts to that would allow them to get their OA publishing fees covered. This ability to potentially influence manuscript submission choice - which incidentally worked far better for article than for book manuscripts- was one of the most rewarding findings of the whole initiative.

The list of most popular journals for this APC funding initiative is included in table 4 below. The list does in fact show the above-mentioned disciplinary bias: while there are a few well-known multidisciplinary titles on the list such as PLOS ONE or Scientific Reports, most of the preferred fully Open Access journal titles chosen by FP7-funded researchers belonged to either biomedical or earth science disciplines. 
Table 4. Distribution of granted funding requests by journal title $(n>5)$

\begin{tabular}{|c|c|c|c|}
\hline Journal title & Publisher & No of funded requests & $\%$ \\
\hline Scientific Reports & $N P G$ & 128 & 12.86 \\
\hline PLOS ONE & PLOS & 92 & 9.25 \\
\hline Nature Communications & NPG & 47 & 4.72 \\
\hline Sensors & $M D P I$ & 28 & 2.81 \\
\hline Atmospheric Chemistry and Physics & Copernicus & 24 & 2.41 \\
\hline Optics Express & OSA & 22 & 2.21 \\
\hline Frontiers in Plant Science & Frontiers & 20 & 2.01 \\
\hline Biogeosciences & Copernicus & 17 & 1.71 \\
\hline Frontiers in Microbiology & Frontiers & 14 & 1.41 \\
\hline Frontiers in Psychology & Frontiers & 14 & 1.41 \\
\hline Cell Reports & Cell Press/Elsevier & 12 & 1.21 \\
\hline BMC Genomics & BioMed Central & 11 & 1.11 \\
\hline Environmental Research Letters & $I O P$ & 11 & 1.11 \\
\hline Ecology and Evolution & Wiley & 11 & 1.11 \\
\hline Energies & MDPI & 10 & 1.01 \\
\hline PLoS Computational Biology & PLoS & 8 & 0.80 \\
\hline New Journal of Physics & $I O P$ & 8 & 0.80 \\
\hline BMC Bioinformatics & BioMed Central & 7 & 0.70 \\
\hline Frontiers in Marine Science & Frontiers & 6 & 0.60 \\
\hline
\end{tabular}

The policy guidelines for the FP7 Post-Grant Open Access Pilot were designed to fund the Open Access publishing costs for a range of outputs beyond journal articles. It was anticipated at the start of the initiative that the vast majority of post-grant publications would be journal articles, but there was also a deep interest in exploring the workflows associated with book and book chapter publishing. For designing the OpenAIRE system described above it was also important to see to what extent the different processes might be covered by a single platform that was essentially based on the characteristic stages for the publication of journal articles. The coverage of Book Processing Charges (BPCs) provided an opportunity to examine the book publishing market and the behaviour of FP7-funded book authors, an input that was eventually fed into the Knowledge Exchange-funded 'landscape study on open access and monographs' that was being carried out at the same time (Ferwerda; Pinter; Stern, 2017).

The distribution of funded outputs by document type does show this strong predominance of journal articles: $93 \%$ or 995 of 1,074 funded works. Relevant samples for other types of outputs were also collected, such as 61 books (monographs and edited volumes) or $5.7 \%$ of the total and 16 book chapters (1.5\%). Best practices in funder-publisher collaboration were implemented for books and book chapters with stakeholders like Ubiquity Press and River Publishers.

\subsection{Average $A P C$ fee and the no-hybrid funding policy}

The average APC fee paid by the FP7 Post-Grant OA Pilot was closely monitored for the whole duration of the initiative. With a $€ 2,000$ funding cap in place for the funding of journal articles, there was a widespread concern at the pilot kickoff that APCs might artificially rise to match such maximum amount of funding. The no-hybrid funding policy meant a certain safeguard in this regard, given it's well known that average APC fees for fully Open Access titles are significantly lower than those typically applied by hybrid journals (Frantsvåg, 2015), but the need was still felt to carefully watch the evolution of this average payment per article.

At the start of the initiative the average APC payment was calculated every two months and included in every progress report that was produced, see an example in figure 4 below. This analysis showed a small, gradual increase that was not due to the raising APC fees charged by publishers, but to the growing presence of partial payments for the maximum $€ 2,000$ funding for APCs that exceeded the funding cap (such as for instance Nature Communications). The introduction of the pre-paid accounts with a number of publishers made it more difficult to monitor of the average expense because these funds were internally managed by the publishers, but they would still be checked whenever a reporting spreadsheet was delivered and uploaded into the FP7 Post-Grant Open Access Pilot system in Athens. This checking showed for instance that the APC fees charged within the pre-paid agreement with BioMed Central tended to be higher than the global average for the whole initiative, but they would usually be balanced by the lower fees charged by Copernicus.

The figure below shows the evolution of the average APC payment during the first months of the initiative. Once the reporting feature in the OpenAIRE system became fully functional, these averages were just taken from the system itself instead of calculated. As of Feb $28^{\text {th }}, 2018$, the average value shown on the system is $€ 1,473$, which is nearly the same figure that was reported at the end of Nov 2016. 
These average values for the FP7 Post-Grant OA Pilot are very much in line with what can be expected from a no-hybrid policy. Although slightly higher than the average APC payments reported by German institutions implementing the Gold Open Access policy for the German Research Foundation (DFG) (Jahn; TuIlney, 2016), this was due to the fact that the DFG policy would refuse to fund APCs higher than the funding cap, while the FP7 post-grant pilot offered partial funding for its $€ 2,000$ maximum funding allocation. The figure for the distribution of APC payments by price range (Fig. 5) shows that the maximum $€ 2,000$ payments were in fact the most frequent ones, and this meant a permanent upwards push for the average APC payment. This is a relevant aspect to be kept in mind by any funding mechanism that includes capped APCs within its policy guidelines.

The average values we have recorded are in any case significantly lower than those arising from APC funding initiatives that support hybrid titles, such as those run by funders like the Research Councils UK or the Wellcome Trust in the United Kingdom.

The concerns about this no-hybrid policy expressed by authors in certain disciplines have already been addressed in section 1.4 above, but the vast majority of researchers who contacted the support desk for the initiative would just accept its policy guidelines and explore the options for qualifying for funding. A no-hybrid policy with the appropriate quality checks to avoid predatory publishing improves the cost-effectiveness for funding initiatives run by research funders and institutions, while providing an increasingly wide range of fully Open Access publishing outlets for nearly every research discipline. Moreover, as an additional and positive side-effect, a no-hybrid policy will often require specific advocacy towards funded authors in order to explain the difference between hybrid and fully OA titles and to explain the reasons behind this policy choice by the research funder. The gradual popularisation of offsetting agreements may seem to suggest that no-hybrid policies do not provide a sufficiently solid mechanism for ensuring a more efficient Open Access funding. However, most UK institutional Open Access funds set up on top of the Open Access funding (block grants) directly received from funders like RCUK or the Wellcome Trust are based on a no-hybrid policy. Furthermore, whenever these funders' block grants allowing hybrid Open Access suffer excessive spending pressure at institutions, the triggering of a no-hybrid policy is an almost automatic mechanism to ease such pressure and keep spending under control.

\subsection{Rejected requests}

According to the information kept in the OpenAIRE system, the total number of rejected requests during the whole initiative was 382 . This figure is only partially accurate due to the fact that the switch to the automated system monitoring meant a methodological change in the way these rejections were recorded. While during the initial manual stage every rejected request was listed in a table, including those arising from consultations via email, the automated phase required a funding request to be submitted to the system for its rejection to be recorded in it, and failed to catch the numerous rejections that took place via individual communication with the authors. 
A detailed analysis of the figures is nevertheless available for the last manual snapshot for rejected requests that was taken on Nov $30^{\text {th }}, 2016$, i.e. 18 months into the funding initiative, as shown in the $8^{\text {th }}$ progress report for the project (De-Castro, 2016c). At this stage, with 700 funded requests, the number of rejected ones was 241, i.e. approximately one quarter of the total, see table below. The reasons for the rejection were also recorded, showing that the overwhelming cause for rejection (77\%) was a funding request for a manuscript accepted in a hybrid journal.

Given the relevance of the no-hybrid policy for this funding initiative, figures were collected for the publishers associated with the rejections due to requests for funding in hybrid titles. The results as of Nov $30^{\text {th }}, 2016$ are shown below, with the five top publishers making up $60 \%$ of the total number of rejected 'hybrid' requests.

\section{Some lessons learnt}

A few findings arising from this FP7 Post-Grant Open Access Pilot are listed below. These add to the facts and figures shown above. They have broadly been classified in sections, the first of which includes findings that may be of interest for research libraries. An additional one is aimed to be useful for research funders that wish to fund Open Access publishing fees. A relevant aspect to be kept in mind is that these conclusions are not always directly supported by the previous facts and figures, but also based in the numerous conversations held with funded researchers under this initiative which have not been reported elsewhere.

\subsection{Lessons learnt - for research libraries}

\section{APC fee funding as a 'carrot' for dissemination purposes}

Most Open Access policies are based on the application of a 'stick' closely linked to the concept of 'compliance'. As opposite to this, an initiative to fund Open Access publishing fees or APCs is based on a 'carrot' approach. It's the sole case where the research support team will typically not need to chase researchers to ensure 'compliance', but authors themselves who will reach out to the research support team in order to inquiry about the eligibility for funding under a specific initiative. This provides an invaluable opportunity for Open Access advocacy purposes, as authors will frequently want to know what the specific requirements are to meet specific eligibility purposes. Within this specific APC funding initiative the advice provided to authors has often extended beyond the EC Open Access policies and into related areas such as Research Data Management. This is something that can be replicated from institutional research support services that run their own APC funding initiatives.

\section{The funded-project-driven approach to dissemination}

Because this FP7 Post-Grant Open Access Pilot has been run on behalf of a research funder (the European Commission), the approach followed for its implementation has been strongly funded project-led (FP7 project-led in this specific case). This is in strong contrast to the regular approach traditionally applied at research libraries, which is rather output-led (where outputs can be specific publications or datasets). It is not difficult however to test the funded project-driven approach from institutional research support services whenever the appropriate institutional systems are at hand -typically meaning project databases or research information management systems.

\section{"Libraries (and institutions) are very bad at collecting money"}

Almost every attempt made from this initiative to allow research libraries to recover part of their non-insignificant expenditure in publication costs (either by transferring block grants to them or by reimbursing APC fees paid upfront by them) have faced massive administrative barriers from various institutional departments devoted
Table 5. Total number of rejected requests by cause (data as of Nov $\left.30^{\text {th }}, 2016\right)$

\begin{tabular}{|l|c|}
\hline Total number of rejected requests & 241 \\
\hline manuscripts accepted in hybrid journals & 186 \\
\hline - previously published articles & 50 \\
\hline - ongoing project (not post-grant) & 15 \\
\hline - unpublished (repository) paper & 6 \\
\hline - refused by project coordinator & 4 \\
\hline - non-existing journals & 3 \\
\hline - not Open Access & 3 \\
\hline - project no longer eligible & 3 \\
\hline - other & 4 \\
\hline
\end{tabular}

Table 6. Rejected funding requests for hybrid journals by publisher for $n>2$ (Nov 30 $\left.{ }^{\text {th }}, 2016\right)$

\begin{tabular}{|l|c|c|}
\hline \multicolumn{1}{|c|}{ Publisher } & \multicolumn{1}{|c|}{$\begin{array}{c}\text { Rejected } \\
\text { funding requests }\end{array}$} & $\%$ \\
\hline Elsevier & 43 & 23.12 \\
\hline Wiley & 28 & 15.05 \\
\hline Springer & 17 & 9.14 \\
\hline IEEE & 14 & 7.53 \\
\hline OUP & 10 & 5.38 \\
\hline Taylor \& Francis & 8 & 4.30 \\
\hline $\begin{array}{l}\text { Nature Publishing Group; } \\
\text { Royal Society of Chemistry }\end{array}$ & 5 & 2.69 \\
\hline $\begin{array}{l}\text { American Chemical Society; } \\
\text { American Meteorological Society; } \\
\text { American Society of Microbiology; } \\
\text { JoVE; } \\
\text { Institute of Physics }\end{array}$ & 3 & 1.61 \\
\hline
\end{tabular}

Initiatives for supporting APC payments are the quintessential 'carrot': it's the sole case where the Open Science support team will not need to chase researchers to ensure 'compliance', but authors themselves will instead reach out to the research support team in order to inquiry about the eligibility for funding under a specific initiative 
to their administration, especially finance. A project partner summarised the dispiriting situation in the one-liner above. Any honest reflection on a 'broken' scholarly communications landscape should look into this issue besides analysing potentially questionable behaviours by publishers.

\section{Research support and its many stakeholders}

The range of research-performing organisations featured as project partners in EU-funded projects extends way beyond the institutions usually represented in Open Access working groups and practitioners' forums. As a result, the level of awareness and the opportunities for dissemination quickly decrease outside this circle of experts. The communication side of this funding initiative has tried to address this divide via associations like EAHIL (European Association for Health Information and Libraries) (De-Vries, De-Castro, 2016) or like EUPMAN, the EU-funded project managers' association in the Netherlands. Research libraries at universities are however far better placed to spread their expertise in the area to close-lying actors like university hospitals or SMEs. The opportunities for extending the Open Access advocacy into organisations connected to institutions via funded projects are there for dynamic leaderships to explore.

\subsection{Lessons learnt - for research funders}

\section{It is possible to influence researchers' behaviour via carefully managed APC funding initiatives}

The level of awareness-raising that an APC funding initiative makes possible with regard to funded researchers is very significant. Specific actions like directly getting involved in the way a specific policy is implemented or in an attempt to align policies across funders as closely as possible can be of much help in this regard. Some funders are already aware of this and are doing an excellent job in directly reaching out to their funded authors on top of the implementation efforts carried out by institutions, but this is far from being a generalised area of activity yet.

\section{Pros and cons of transferring the funding policy implementation to institutions}

By transferring the responsibility for the dissemination and implementation of APC funding initiatives to institutions, research funders may achieve a much more effective result, as these lie closer to researchers and are able to more easily integrate a new funding opportunity into their regular work. However, the first-hand insight that a centralised approach provides into the multiple issues in the area of scholarly communications may to some extent be lost in the process. This first-hand insight usually informs the next round of developments -such as the current activity around Open Research platforms- making it a very useful input to fine-tune previous approaches.

\section{A number of pieces are still missing in the infrastructure required to effectively run an APC funding initiative}

The Open Access community as a whole still lacks key pieces of infrastructure that would make it much easier to roll out an initiative to fund Open Access publishing fees. Some of these missing bits and pieces include a comprehensive database of current APC fees, an up-to-date list of hybrid titles or lists (even at national level) of available institutional Open Access funds. Because of the intensive technical collaboration with specific publishers involved in the initiative, this $F P 7$ Post-Grant Open Access Pilot has caught a glimpse of a landscape where all these could be produced via a legitimate collaboration with publishers carried out under the well-informed watch of research funders.

\section{The value of no-hybrid policies}

As the institutional advocacy effort on Open Access publishing becomes more effective among authors, there are clear signs that the funding for APC fees provided by specific research funders and/or the institutions themselves is often not enough to cover Gold Open Access for the whole institutional research output, not even with the additional support offered by the offsetting deals (where available). Some filtering mechanism is required in these cases to decide what to fund with the available Open Access funds, and institutions are frequently reverting to the no-hybrid policy to address the issue. These no-hybrid policies allow institutions -and especially libraries, as the units typically implementing the Open Access funding initiatives at institutions- not to be forced to discriminate on the grounds of research discipline or researcher seniority. A no-hybrid policy allows authors to become eligible for funding themselves through their choice of a publishing venue, and provides a very effective instrument for educational purposes around Open Access.

\section{The APC funding model still needs to be significantly fine-tuned}

While APCs are a generally effective business model for achieving immediate Open Access, numerous shortcomings still persist and have surfaced in the course of this initiative. The very complex many-to-many relation between institutions and publishers remains a maze that few authors are able to navigate on their own. The most relevant issue for policy-makers is however that the current APC prices result in whole regions being shut off
The fact that authors this day and age are frequently still paying their APCs from their own pockets was an unexpected finding from this pilot. While instruments like the offsetting deals make Gold Open Access eligibility far more democratic, new models still need to be found that help levelling the playing field across countries without disproportionately benefitting legacy publishers 
from this business model. ${ }^{12}$ Also that too many researchers remain ineligible for APC funding under schemes coupled to funded project acknowledgement: the fact that authors this day and age are frequently still paying their APCs from their own pockets was an unexpected finding from this pilot. While instruments like the offsetting deals make Gold Open Access eligibility far more democratic, new models still need to be found that help levelling the playing field across countries without disproportionately benefitting legacy publishers.

\section{Notes}

1. Expenses on APC fees can now be included as part of the research dissemination costs in the grant applications for H2020 projects, see section 3, step 2 "Open Access publishing" (p. 7) in "Guidelines to the Rules on Open Access to Scientific Publications and Open Access to Research Data in Horizon 2020". This option was not available for FP7 projects. http://bit.ly/19regtt

2. No APC funding initiative was specifically targeting post-grant publications by the time the FP7 Post-Grant Open Access Pilot was designed and launched. Shortly after its nominal 2-year life was completed, a similar national-level initiative was launched by the German Federal Ministry for Education and Research (BMBF): https://www.bmbf.de/foerderungen/bekanntmachung-1404.html

3. The project grant for the FP7 Post-Grant Open Access Pilot included a remit to produce a market/economic impact study with the purpose of "contributing a vision of what a sustainable and competitive open access publishing market should look like". This was realised via the report "Towards a competitive and sustainable Open Access publishing market in Europe' produced by Research Consulting Ltd: https://blogs.openaire.eu/wp-content/uploads/2017/03/OA-market-report-28Final-13-March-201729-1.pdf

4. OpenAIRE system for the FP7 Post-Grant Open Access Pilot. https://postgrantoapilot.openaire.eu

5. The number of organisations potentially eligible for funding under the FP7 Post-Grant Open Access Pilot amounted to tens of thousands

6. It's far more frequent for smaller research funders running a centralised workflow to make available an online form for requesting APC funding, see for instance the one for the $B M B F$ post-grant initiative at https://www.bildung-forschung.digital/files/PostGrantFund.pdf

or the Chief Scientist Office (CSO)'s one in Scotland on:

http://www.cso.scot.nhs.uk/wp-content/uploads/Form6a-Application-for-Open-Access-Publication-Costs-July-2016.doc

7. The Chronos platform designed and developed by the Bill and Melinda Gates Foundation as "a new service to simplify the process of research publishing" is one of the most innovative recent approaches to a funder-driven, centralised workflow:

http://chronos-oa.com

This involves coupling a manuscript submission system on the funder's side to the publishers' systems

8. Being a publicly-funded initiative, transparency was seen as a key aspect in the implementation of the FP7 PostGrant Open Access Pilot. The signing of the first pre-payment agreement was accordingly announced by this post "First pre-payment contract signed by the FP7 Post-Grant Open Access Pilot" on the OpenAIRE blog on:

https://blogs.openaire.eu/?p=718

making openly available the contract that was signed so that other publishers could be able to assess their potential interest in joining the scheme

9. The constant and very quick evolution of the Open Access landscape has already seen the arrival of new initiatives around the harmonisation of APC funding workflows such as the Copyright Clearing Center's RightsLink:

http://go.copyright.com/rightslinkforoa\#articlepublicationcharges

10. While the UK is the friendliest country towards the Gold Open Access model in Europe, with multiple funding sources for APC payment coverage at institutional level, Spain has officially adopted a Green Open Access policy based on a solid institutional repository network and there's little support for APC funding in the country beyond scattered institutional Open Access funds

11. Radboud and Bielefeld were the two institutions that received block grant transfers from the FP7 Post-Grant OA Pilot.

12. "We agree that an OA expansion policy, through the payment of APC fees, is impossible to undertake from a financial point of view for the participant countries. To not create grants to pay a publication in OA-APC magazines is recommended to the institutions": Statement by the First [Research-Funding] Consortium Assembly from Ibero-America and Caribbean countries, Ciudad Juárez, México, August $31^{\text {st }}$ and September $1^{\text {st }}, 2017$ :

http://reuniondeconsorcios.conricyt.mx/index.php/primera-reunion/declaraciones/?lang=en 


\section{References}

BMBF (2017). "Richtlinie zur Förderung von Open Access-Publikationen aus abgeschlossenen BMBF-geförderten Projekten (Post-Grant-Fund)". Bundesministerium für Bildung und Forschung: Bekanntmachungen.

https://www.bmbf.de/foerderungen/bekanntmachung-1404.html

De-Castro, Pablo (2015). "Funded journal titles by the EC FP7 Post-Grant Open Access Pilot". OpenAIRE Blog, 25 Nov. https://www.openaire.eu/national-workshops/funded-journal-titles-by-the-ec-FP7-post-grant-open-access-pilot-1

De-Castro, Pablo (2016a). "OpenAIRE shares FP7 Post-Grant OA Pilot data on APC payments with OpenAPC". OpenAIRE Blog, 24 Nov.

https://www.openaire.eu/national-workshops/OpenAIRE-shares-FP7-post-grant-oa-pilot-data-on-apc-payments-withopenapc-1

De-Castro, Pablo (2016b). "Alternative funding mechanism workshop for APC-free open access journals (Dec. 19 $9^{\text {th }}, \mathrm{KB}$, The Hague)". OpenAIRE Blog, 23 Dec.

https://www.openaire.eu/national-workshops/alternative-funding-mechanism-workshop-for-apc-free-open-accessjournals-dec-19th-kb-the-hague-1

De-Castro, Pablo (2016c). " $8^{\text {th }}$ progress report for the FP7 Post-Grant Open Access Pilot". OpenAIRE Blog, 5 Dec. https://www.openaire.eu/blogs/8th-progress-report-for-the-FP7-post-grant-open-access-pilot-1

De-Vries, Saskia; De-Castro, Pablo (2016), "The EC FP7 Post-Grant Open Access Pilot funding initiative for Open Access publishing fees: a dissemination challenge". Proceedings $15^{\text {th }}$ EAHIL Conference.

http://www.bvsspa.es/eahil2016/wp-content/uploads/2016/06/F6.pdf

DFG (2017). "DFG funding for Open Access". Deutsche Forschungsgemeinschaft: Research Funding.

http://www.dfg.de/en/research_funding/programmes/infrastructure/lis/open_access/funding_open_access/index.html

European Commission (2017). "Extension of the OpenAIRE FP7 Post-Grant Open Access Pilot". Digital Single Market Projects Story, 11 May.

https://ec.europa.eu/digital-single-market/en/news/extension-openaire-fp7-post-grant-open-access-pilot

European Union (2015). “CORDIS - EU research projects under FP7 (2007-2013)”. EU Open Data Portal, 29 July.

https://data.europa.eu/euodp/data/dataset/cordisfp7projects

Ferwerda, Eelco; Pinter, Frances; Stern, Niels (2017). "Knowledge exchange landscape study on open access and monographs: Policies, funding and publishing in eight European countries". Jisc Repository, 6 Oct.

http://repository.jisc.ac.uk/6693/1/Landscape_study_on_OA_and_Monographs_Oct_2017_KE.pdf

Franck, Gwen (2018). "OpenAIRE FP7 Post-Grant Open Access Pilot: datasets and reporting”. Zenodo, 26 June. https://doi.org/10.5281/zenodo.998041

Frantsvåg, Jan Erik (2015). "Going for true gold: Why the Norwegian Research Council is taking a stand against hybrid OA journals". Digital Science Blog. 3 Feb.

https://www.digital-science.com/blog/guest/going-for-true-gold-why-the-norwegian-research-council-is-taking-astand-against-hybrid-oa-journals

FWF (2014). "Open Access Policy". FWF Research Funding.

https://www.fwf.ac.at/en/research-funding/open-access-policy

Galimberti, Paola (2016). "Implementing the FP7 Post-Grant Open Access Pilot at the University of Milan". OpenAIRE Blog. https://www.openaire.eu/national-workshops/best-practices-in-the-institutional-implementation-of-the-FP7-postgrant-oa-pilot-i-1

Geschuhn, Kai; Stone, Graham (2017). "It's the workflows, stupid! What is required to make 'offsetting' work for the open access transition". Insights, v. 30, n. 3, pp. 103-114.

https://doi.org/10.1629/uksg.391

Jahn, Najko; Tullney, Marco (2016). "A study of institutional spending on open access publication fees in Germany". PeerJ, 4:e2323.

https://doi.org/10.7717/peerj.2323

Jobmann, Alexandra (2018). "Beyond APCs - OpenAIRE workshop on alternative open access publishing business models". Open Access 2020 Blog, 11 Apr.

http://oa2020-de.org/en/blog/2018/04/11/beyondapcs-OpenAIRE-workshop

Morrison, Heather (2015). "Two-thirds of DOAJ journals do not have article processing charges". Sustaining the knowledge commons / Soutenir les savoirs communs blog, 25 May.

https://sustainingknowledgecommons.org/2015/05/25/two-thirds-of-doaj-journals-do-not-have-article-processing-charges 
MPDL (2016). "OA2020: New initiative to boost Open Access". Max Planck Society Newsroom, 21 March. https://www.mpg.de/openaccess/oa2020

Muñoz, Estefanía (2016). "Implementing the FP7 Post-Grant Open Access Pilot at Universidad Politécnica de Madrid". OpenAIRE Blog.

https://www.openaire.eu/national-workshops/best-practices-in-the-institutional-implementation-of-the-fp7-postgrant-oa-pilot-iii-1

OpenAIRE (2016). "Are you publishing your APC-free OA journal on a shoestring?". University College Cork News, 30 Jun. https://www.ucc.ie/en/research/news-events/news/are-you-publishing-your-apc-free-oa-journal-on-a-shoestring-.html

OpenAIRE (2018). "List of OpenAIRE-compatible data providers". OpenAIRE Website.

https://provide.openaire.eu

Pasteur4OA (2014). "Open access policy alignment strategies for European Union research". Pasteur4OA-611742 FP7 project website.

http://www.pasteur4oa.eu

RCUK (2012). "RCUK announces block grants for universities to aid drives to open access to research outputs". UK Council for Graduate Education Newsletter, 8 Nov.

https://bit.ly/2Wq8TVJ

RCUK (2016). "RCUK announces 2016/17 Block Grant for Open Access". Harvard Open Access Tracking Project, 19 Oct. http://tagteam.harvard.edu/hub_feeds/3471/feed_items/2198656

Research Consulting (2017). "Mid-term evaluation of the OpenAIRE Post-grant OA Pilot". LIBER Website, 29 Mar. https://libereurope.eu/wp-content/uploads/2017/03/Annex-OpenAIRE-Pilot-28Final29-3.pdf

Šipka, Pero (2017). "Supporting SCIndeks improvements through alternative funding mechanism: CEON/CEES Project Execution Final Report". CEON/CEES Centre for Evaluation in Education and Science Website.

https://www.ceon.rs/images/pdf/Alternative_Funding_Mechanism.pdf

Van-Gorp, Dirk (2016). "Implementing the FP7 Post-Grant Open Access Pilot at Radboud University/ Radboud University Medical Centre". OpenAIRE Blog, 2 Nov.

https://www.openaire.eu/blogs/best-practices-in-the-institutional-implementation-of-the-FP7-post-grant-oa-pilot-ii-1

Wellcome (2014). "Charity open access fund". Wellcome Trust Funding.

https://wellcome.ac.uk/funding/managing-grant/charity-open-access-fund

\section{Colección EPI Scholar}

\section{Libros científicos de Información, Documentación y Comunicación}

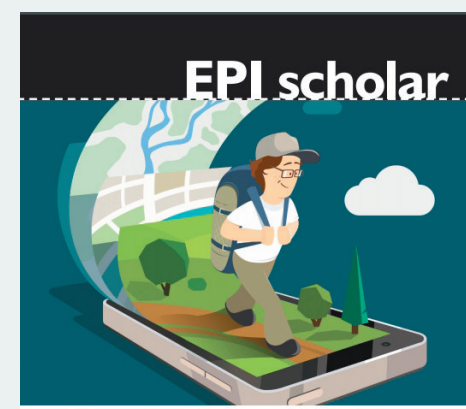

TURISMO RURAL ONLINE PÁGINAS WEB Y REDES SOCIALES GERSÓN BELTRÁN Informacion - Sil EDITORIAL UOC

\section{Turismo rural online. Páginas web y redes sociales de Gersón Beltrán}

Los turistas están conectados en todo momento y se mueven en un entorno social, local y móvil: buscan información en internet antes de ir a su destino y realizan las reservas por anticipado, utilizan el móvil durante su experiencia turística para comunicarse y, tanto durante como tras el viaje, comparten sus opiniones en medios sociales.

Las empresas y destinos turísticos deben adaptarse a esta realidad, en la que lo físico es inseparable de lo online, conformando un entorno híbrido. Paralelamente, los espacios rurales sufren numerosos problemas de desarrollo y despoblación, y el turismo rural constituye una actividad que puede ayudar a revertir esta situación. Las nuevas tecnologías se configuran como herramientas que unen a los turistas conectados con estos espacios.

Este libro ofrece una visión general de la situación del turismo rural online, así como las claves para que las empresas y destinos turísticos logren conectar con los turistas y éstos disfruten de las experiencias únicas que les ofrece el turismo rural.

Beltrán, Gersón (2019). Turismo rural online. Páginas web y redes sociales. Barcelona: El profesional de la información, Editorial UOC, colección EPI Scholar n. 11, 170 pp. ISBN: 9788491803881 

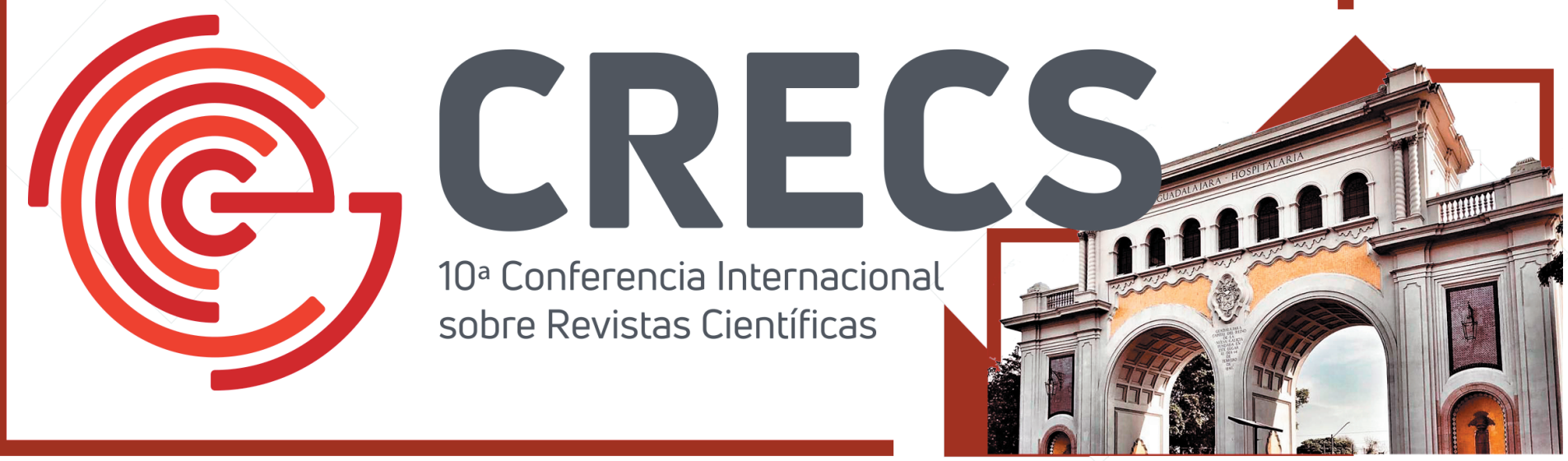

10a Conferencia Internacional sobre Revistas Científicas

\section{3 - 24 DE OCTUBRE UNIVERSIDAD PANAMERICANA \\ 10a Conferencia internacional sobre revistas científicas (CRECS) 2019}

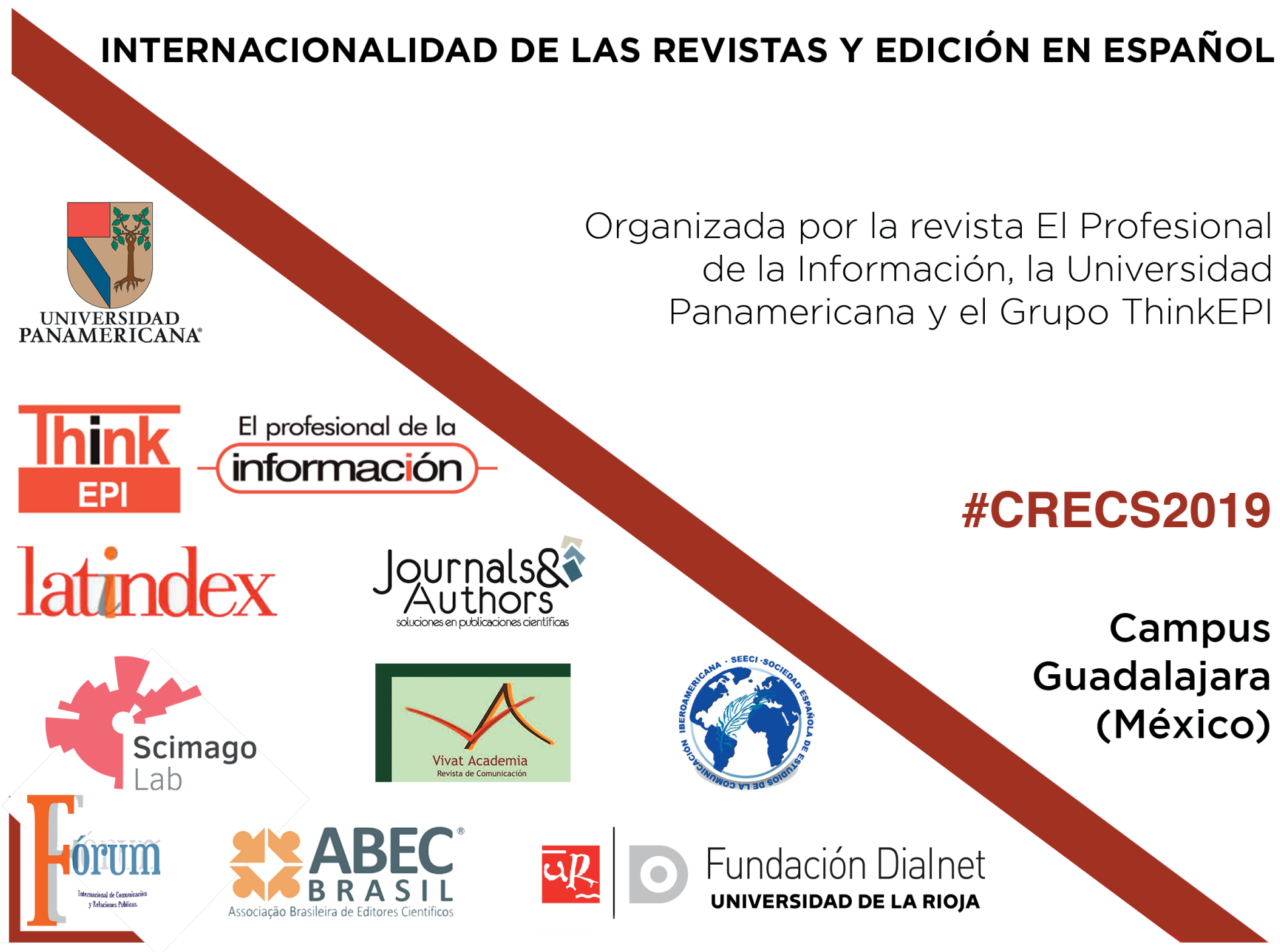

